\title{
Risk assessment of foundation pit construction using cloud model
}

\author{
Tian Xun \\ China Road and Bridge Corporation, Beijing, 100011, China
}

\begin{abstract}
The risk level evaluation of foundation pit construction has the characteristics of fuzziness and randomness. Based on the theory of cloud model, a new model of risk level of foundation pit construction is discussed to comprehensively analyze the fuzziness and randomness of foundation pit construction risk assessment. Firstly, the evaluation index system of foundation pit construction risk level is established according to the field monitoring value, and then the cloud numerical characteristics of each evaluation factor belonging to different risk levels are calculated. According to the cloud digital characteristics of each evaluation factor, the determination degree of each evaluation factor belonging to different risk levels can be obtained. Finally, the weight and determination degree of the evaluation factor can be calculated comprehensively to obtain the comprehensive certainty degree of foundation pit construction risk, so as to determine the foundation pit construction risk level. The results of practical application and comparison with other evaluation methods show that this model is effective and feasible for risk classification of foundation pit construction, and has the advantages of simple calculation process and reliable results, which also provides a reference for the analysis of other similar problems.
\end{abstract}

\section{Introduction}

With the rapid development of urban construction in China, more and more deep foundation pits are being constructed. The foundation pit engineering has become a risky project in the construction project because of its many uncertain factors and complicated surroundings. However, due to the limitation of technology and management level, as well as the lack of objective understanding of engineering risks, foundation pit engineering accidents have occurred frequently in recent years. Therefore, it is necessary to evaluate the risk of foundation pit construction.

Many scholars have discussed the risk assessment of foundation pit construction based on different theories. For example, Huang Hongwei et al., a domestic scholar, identified the risk factors in the construction process of foundation pit engineering through engineering examples, and evaluated the risk during the construction period of foundation pit engineering based on expert investigation method and analytic hierarchy process [1]. Choi et al., He Xixing et al. Evaluated the risk of foundation pit by using fuzzy hierarchical comprehensive evaluation method [23]. Todinov [4] evaluated the risk by using fault tree analysis method. Other scholars evaluated the risk of related projects by Monte Carlo simulation analysis method [5-6] and Bayesian network probability model [7]. Although these methods have made beneficial progress, they seldom consider the influence of fuzziness and randomness on the evaluation results of foundation pit stability at the same time, which is not consistent with the actual risk evaluation of foundation pit construction and has some defects in practical application. For example, it is difficult to determine the membership function in the practical application of fuzzy mathematics. The rough set theory method may delete important evaluation factors in the process of attribute reduction. The artificial neural network method has the bottleneck problem of knowledge acquisition, and the set pair analysis method is difficult to determine the difference coefficient in the evaluation. Therefore, this study takes the monitoring object as the evaluation index of foundation pit construction risk and discusses the improved fuzzy comprehensive evaluation method based on the cloud model theory. The feasibility and effectiveness of this method are verified by comparing with previous research results.

\section{Cloud Model of foundation pit risk assessment}

\subsection{Cloud model theory}

Cloud model is an uncertainty transformation model between qualitative concept and quantitative numerical representation proposed by Li Deyi et al in China, which has been applied in data mining, simulation prediction, evaluation and other fields [8-9]. As an uncertainty model of qualitative and quantitative transformation, cloud model can fully reflect the randomness and fuzziness of language concepts, and is an effective tool to realize

*Corresponding author's e-mail: txy09@163.com 
qualitative and quantitative transformation, among which cloud generator is the key to its practical application.

Assuming $U$ is a quantitative domain presented by a precise figure, $T$ is the qualitative concept corresponding to $U$. If the membership degree of $\mathrm{x}$ to $T$ is a random number with stable tendency, which can be expressed as $\mu_{T}(x) \in[0,1]$. Then the distribution of $\mathrm{x}$ over the domain $U$ is called membership cloud, cloud for short. Each $\mathrm{x}$ is called a cloud drop. The cloud model of qualitative concept $T$ is the mapping from the domain $U$ to the interval $[0,1]$, i.e

$$
\mu_{T}(x): U \rightarrow[0,1], \forall x \in U, x \rightarrow \mu_{T}(x)
$$

\subsection{Normal cloud model}

In this paper, the forward normal cloud generator is used, because the normal cloud model is a new model developed on the basis of normal distribution and fuzzy mathematical concepts. The normal cloud model has the advantage of universality from qualitative concept to quantitative model. If the quantitative value $x \in U$, and $\mathrm{x}$ is a random realization of the qualitative concept $T$, if $x-$ $N\left(E x,\left(\mathrm{E}_{\mathrm{n}}{ }^{\prime}\right)^{2}\right)$, where $E_{n}{ }^{\prime}-N\left(E n, H_{e}{ }^{2}\right)$. The cloud expectation curve equation with normal distribution can be determined by expectation and entropy:

$$
\mu=\exp \left(\frac{-\left(x-E_{x}\right)^{2}}{2\left(E_{n}^{\prime}\right)^{2}}\right)
$$

\subsection{Cloud model parameter calculation of risk assessment indicator}

The risk classification of foundation pit construction is closely related to the selection of evaluation index. In this paper, the monitoring project is used as the evaluation index of foundation pit risk, and the index risk is classified according to certain standards. When selecting specific monitoring items, the items that can directly reflect the risk of foundation pit deformation are mainly. Therefore, the monitoring items with strong sensitivity to the foundation pit deformation are selected in this paper, which are the deep horizontal displacement, the horizontal displacement of the crown beam, the settlement of the column, the axial force, the settlement of the surrounding buildings, and the settlement of the soil outside the pit. The axial force only considers the cumulative index, while the other monitoring items consider the cumulative value and the rate [10]. The risk classification of foundation pit construction is shown in table 1 .

\begin{tabular}{|c|c|c|c|c|c|c|}
\hline \multirow{2}{*}{ Evaluation index } & \multirow{2}{*}{ Monitoring indicators } & \multicolumn{5}{|c|}{ Risk level } \\
\hline & & I & II & III & IV & $\mathrm{V}$ \\
\hline \multirow{2}{*}{$\begin{array}{l}\text { Deep horizontal } \\
\text { displacement }\end{array}$} & Cumulative value (mm) & $0-27$ & $27-31$ & $31-36$ & $36-45$ & $45-54$ \\
\hline & $\begin{array}{l}\text { Displacement rate } \\
\qquad\left(\mathrm{mm} \cdot \mathrm{d}^{-1}\right)\end{array}$ & $0-1.2$ & $1.2-1.4$ & $1.4-1.6$ & $1.6-2$ & $2-2.4$ \\
\hline \multirow{2}{*}{$\begin{array}{l}\text { Horizontal } \\
\text { displacement of } \\
\text { the crown beam }\end{array}$} & Cumulative value (mm) & $0-18$ & $18-21$ & $21-24$ & $24-30$ & $30-36$ \\
\hline & $\begin{array}{c}\text { Displacement rate } \\
\left(\mathrm{mm} \cdot \mathrm{d}^{-1}\right)\end{array}$ & $0-1.2$ & $1.2-1.4$ & $1.4-1.6$ & $1.6-2$ & $2-2.4$ \\
\hline \multirow[b]{2}{*}{ Pillar settlement } & Cumulative value (mm) & $0-12$ & $12-14$ & $14-16$ & $16-20$ & $20-24$ \\
\hline & $\begin{array}{l}\text { Displacement rate } \\
\qquad\left(\mathrm{mm} \cdot \mathrm{d}^{-1}\right)\end{array}$ & $0-1.2$ & $1.2-1.4$ & $1.4-1.6$ & $1.6-2$ & $2-2.4$ \\
\hline Axial force & Cumulative value (mm) & $0-0.42$ & $0.42-0.49$ & $0.49-0.56$ & $0.56-0.7$ & $0.7-0.84$ \\
\hline \multirow{2}{*}{$\begin{array}{l}\text { Settlement of } \\
\text { surrounding } \\
\text { buildings }\end{array}$} & $\begin{array}{l}\text { Displacement rate } \\
\left(\mathrm{mm} \cdot \mathrm{d}^{-1}\right)\end{array}$ & $0-18$ & $18-21$ & $21-24$ & $24-30$ & $30-36$ \\
\hline & Cumulative value (mm) & $0-1.2$ & $1.2-1.4$ & $1.4-1.6$ & $1.6-2$ & $2-2.4$ \\
\hline \multirow{2}{*}{$\begin{array}{l}\text { The soil outside } \\
\text { the pit settled }\end{array}$} & $\begin{array}{l}\text { Displacement rate } \\
\left(\mathrm{mm} \cdot \mathrm{d}^{-1}\right)\end{array}$ & $0-18$ & $18-21$ & $21-24$ & $24-30$ & $30-36$ \\
\hline & Cumulative value (mm) & $0-1.2$ & $1.2-1.4$ & $1.4-1.6$ & $1.6-2$ & $2-2.4$ \\
\hline
\end{tabular}

Table 1. Risk classification of foundation pit construction.

According to the concept of cloud model, it can be known that the risk rating factor of foundation pit can be calculated according to the following formula for the cloud digital characteristics $\left(E_{x} E_{n} H_{e}\right)$ of a certain level standard:

$$
\begin{gathered}
E x=\frac{C_{\text {min }}+C_{\text {max }}}{2} \\
E n=\frac{C_{\text {max }}-C_{\text {min }}}{6}
\end{gathered}
$$

$$
H e=k
$$

where $C_{\min }$ and $C_{\max }$ are the minimum and maximum boundaries of a certain grade standard respectively. $k$ is a constant, which can be adjusted according to the fuzzy threshold of the variable. According to formula (3)-(5), the cloud model parameters of risk rating factor of foundation pit can be calculated as shown in table 2 . 
Table 2. Cloud model parameters $\left(E_{x} E_{n} H_{e}\right)$ of risk rating factor for foundation pit.

\begin{tabular}{cccccc}
\hline \multirow{2}{*}{$\begin{array}{c}\text { Evaluation } \\
\text { index }\end{array}$} & \multicolumn{5}{c}{ Risk level } \\
\cline { 2 - 6 } & $\mathrm{I}$ & $\mathrm{II}$ & $\mathrm{III}$ & $\mathrm{IV}$ & $\mathrm{V}$ \\
\hline $\begin{array}{c}\text { Deep horizontal } \\
\text { displacement }\end{array}$ & $(13.5,4.5,0.1)$ & $(29,0.67,0.1)$ & $(33.5,0.83,0.1)$ & $(40.5,1.5,0.1)$ & $(49.5,1.5,0.1)$ \\
Horizontal & $(0.6,0.2,0.01)$ & $(1.3,0.03,0.01)$ & $(1.5,0.03,0.01)$ & $(1.8,0.07,0.01)$ & $(2.2,0.07,0.01)$ \\
displacement of & $(9,3,0.1)$ & $(19.5,0.5,0.1)$ & $(22.5,0.5,0.1)$ & $(27,1,0.1)$ & $(33,1,0.1)$ \\
the crown beam & $(0.6,0.2,0.01)$ & $(1.3,0.03,0.01)$ & $(1.5,0.03,0.01)$ & $(1.8,0.07,0.01)$ & $(2.2,0.07,0.01)$ \\
& $(6,2,0.1)$ & $(13,0.3,0.1)$ & $(15,0.3,0.1)$ & $(18,0.7,0.1)$ & $(22,0.7,0.1)$ \\
Pillar settlement & $(0.6,0.2,0.01)$ & $(1.3,0.03,0.01)$ & $(1.5,0.03,0.01)$ & $(1.8,0.07,0.01)$ & $(2.2,0.07,0.1)$ \\
Axial force & $(0.21,0.07,0.01)$ & $(0.46,0.01,0.01)$ & $(0.53,0.01,0.01)$ & $(0.63,0.02,0.01)$ & $(0.77,0.02,0.01)$ \\
Settlement of & $(9,3,0.1)$ & $(19.5,0.5,0.1)$ & $(22.5,0.5,0.1)$ & $(27,1,0.1)$ & $(33,1,0.1)$ \\
surrounding & $(0.6,0.2,0.01)$ & $(1.3,0.03,0.01)$ & $(1.5,0.03,0.01)$ & $(1.8,0.07,0.01)$ & $(2.2,0.07,0.01)$ \\
buildings & $(9,3,0.1)$ & $(19.5,0.5,0.1)$ & $(22.5,0.5,0.1)$ & $(27,1,0.1)$ & $(33,1,0.1)$ \\
The soil outside & $(1.3,0.03,0.01)$ & $(1.5,0.03,0.01)$ & $(1.8,0.07,0.01)$ & $(2.2,0.07,0.01)$ \\
the pit settled & $(0.6,0.2,0.01)$ & & & &
\end{tabular}

After obtaining the digital characteristics, the cloud model diagram is generated by using the forward cloud generator. Due to space constraints, only the cloud models of accumulation value and horizontal displacement rate of deep and crown beams are given here, as shown in Figure 1-4 respectively. The abscissa represents the value of the evaluation factor and the ordinate represents the determination of the corresponding risk level.

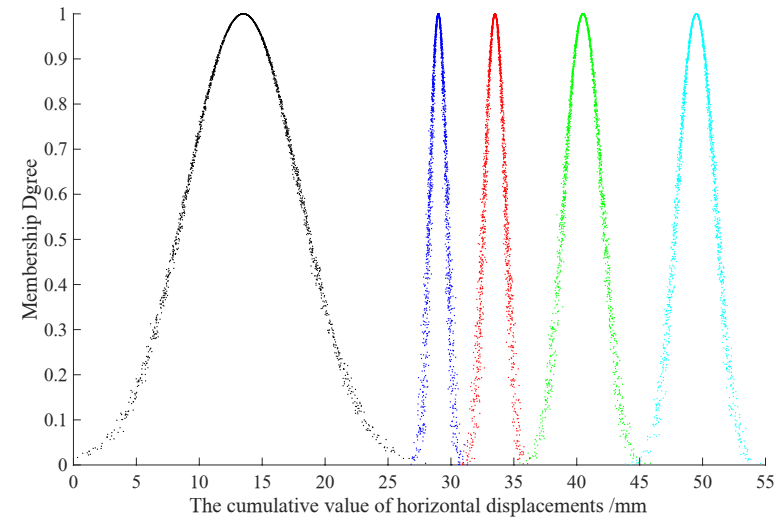

Figure 1. The cumulative value of horizontal displacements.

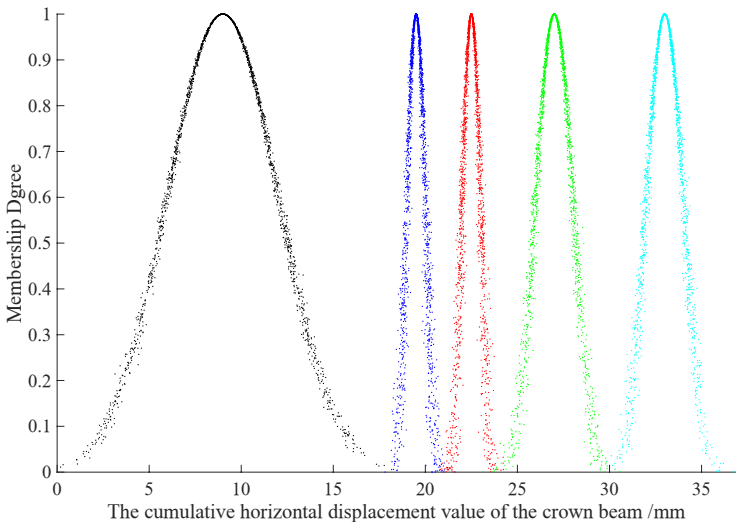

Figure 2. The cumulative value of horizontal displacements of the crown beam.

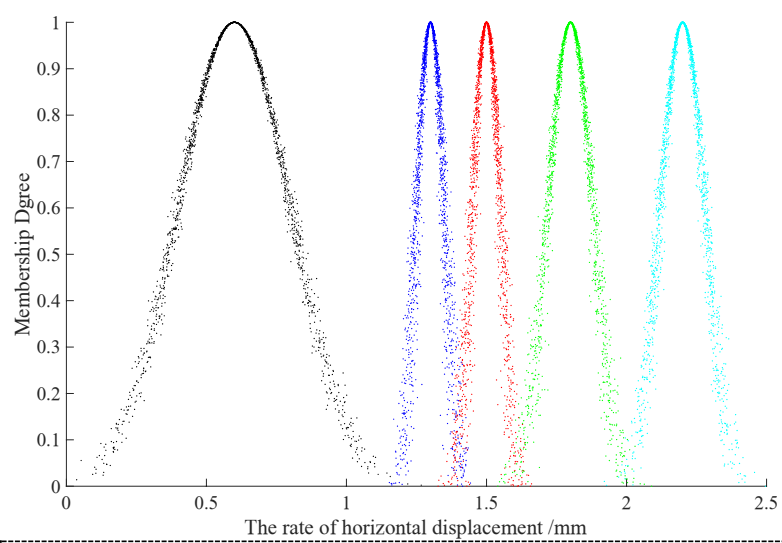

Figure 3. The rate of horizontal displacements.

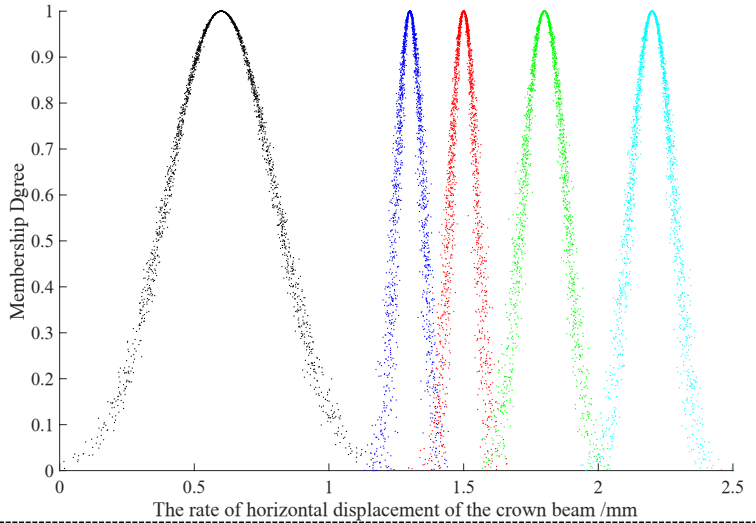

Figure 4. The rate of horizontal displacements of the crown beam. 
According to the algorithm of forward state cloud generator, the determination degree $\mu$ of a certain index data belonging to a certain level of cloud can be calculated. Combined with the weight of the evaluation factor $\omega_{j}$, the comprehensive certainty degree $U$ is finally calculated. According to the maximum value of comprehensive certainty degree, the risk level of foundation pit is determined by formula

$$
U=\sum_{j=1}^{m} \mu \omega_{j}
$$

\section{$3 \quad$ Application instance}

In order to verify the correctness and validity of the model, the data in literature [10] were used for application and verification comparative analysis. Instances of deep foundation pit risk grade evaluation index selected horizontal displacement, crown displacement of beam, pillar, axial force, surrounding building subsidence and the pit soil subsidence rate and the cumulative values, six indexes categories into risk-free I, low-risk II, general risk III, high-risk IV and high riskV. Risk level evaluation index measured values of foundation pit are shown in table 3 .

Table 3. Risk level evaluation index measured values of foundation pit.

\begin{tabular}{lccc}
\hline Evaluation indicators & $\begin{array}{c}\text { Cumulative value } \\
(\mathrm{mm})\end{array}$ & $\begin{array}{c}\text { Displacement rate } \\
\left(\mathrm{mm} \cdot \mathrm{d}^{-1}\right)\end{array}$ & $\begin{array}{c}\text { Cumulative value } \\
\text { /Design value }\end{array}$ \\
\hline $\begin{array}{l}\text { Deep horizontal displacement } \mathrm{A}_{1} \\
\text { Horizontal displacement of the } \\
\text { crown beam } \mathrm{A}_{2}\end{array}$ & 24.59 & 2.12 & 2.32 \\
$\begin{array}{l}\text { Pillar settlement } \mathrm{A}_{3} \\
\text { Axial force } \mathrm{A}_{4}\end{array}$ & 28.5 & 1.52 & 0.53 \\
$\begin{array}{l}\text { Settlement of surrounding buildings } \\
\mathrm{A}_{5}\end{array}$ & 5.61 & \\
The soil outside the pit settled $\mathrm{A}_{6}$ & 13.83 & 1.36 & \\
\hline
\end{tabular}

Based on the above model, the inter-class boundary values $C_{\min }$ and $C_{\max }$ corresponding to each indicator can be obtained from table 1 , and the digital characteristics of the cloud model of each risk level can be obtained by substituting formula (3) - (5). Through formula (2), the certainty degree of the cumulative value and rate of all risk factors are shown in table 4.

Table 4. Risk level certainty degree of cumulative value and rate.

\begin{tabular}{ccccccccccc}
\hline \multirow{2}{*}{$\begin{array}{c}\text { Risk } \\
\text { factors }\end{array}$} & \multicolumn{4}{c}{ Risk level of cumulative value } & \multicolumn{5}{c}{ Risk level of rate } \\
\cline { 2 - 11 }$y$ & I & II & III & IV & V & I & II & III & IV & V \\
\hline $\mathrm{A}_{1}$ & 0.0394 & 0.9012 & 0 & 0 & 0 & 0 & 0.1669 & 0 & 0 & 0 \\
$\mathrm{~A}_{2}$ & 0 & 0 & 0 & 0.6065 & 0.0796 & 0 & 0.0626 & 0 & 0 & 0 \\
$\mathrm{~A}_{3}$ & 0.0173 & 0.9891 & 0 & 0 & 0 & 0.0021 & 0.8791 & 0.9560 & 0.0198 & 0 \\
$\mathrm{~A}_{4}$ & 0.0025 & 0.0054 & 0.9898 & 0 & 0 & 0.0025 & 0.0054 & 0.9898 & 0 & 0 \\
$\mathrm{~A}_{5}$ & 0.1117 & 0.6633 & 0 & 0 & 0 & 0.0073 & 0.9905 & 0.1103 & 0 & 0 \\
$\mathrm{~A}_{6}$ & 0.1040 & 0.6835 & 0 & 0 & 0 & 0 & 0.7351 & 0.1103 & 0 & 0 \\
\hline
\end{tabular}

According to formula (6), the comprehensive certainty degree of the instances can be obtained. Then the risk level of foundation pit can be determined based on the level of the maximum comprehensive certainty degree. In order to facilitate the comparative analysis with the previous research results and verify the reliability and correctness of the model, the weights of each evaluation factor determined in literature [10] are used here. The comprehensive evaluation results of foundation pit risk level based on the cloud model and the comparative analysis results with the methods in literature [10] are shown in table 5.

Table 5. Comprehensive evaluation result and comparison of risk grade of foundation pit.

\begin{tabular}{ccccccc}
\hline \multicolumn{4}{c}{ Comprehensive certainty degree } & \multicolumn{2}{c}{ Comprehensive risk level } \\
\hline$U(\mathrm{I})$ & $U(\mathrm{II})$ & $U(\mathrm{III})$ & $\mathrm{U}(\mathrm{IV})$ & $U(\mathrm{~V})$ & $\begin{array}{c}\text { Method of this } \\
\text { paper }\end{array}$ & $\begin{array}{c}\text { Probabilistic } \\
\text { valuation method }\end{array}$ \\
0.0144 & 0.4138 & 0.4880 & 0.0744 & 0.0094 & III & III \\
\hline
\end{tabular}

According to the results in table 4, the classification results of the model in this paper are consistent with the results of the method in literature [10], which indicate that the application of cloud model to evaluate the risk level of foundation pit is effective and feasible. The risk level of foundation pit is a qualitative concept, and the classification process is influenced and controlled by many uncertain factors. The application of cloud digital characteristics to express the uncertainty has advantages. The relationship between fuzziness and randomness in 
foundation pit risk evaluation can be fully revealed, and the results are convenient for engineering application.

\section{Conclusion}

The risk assessment of foundation pit construction is influenced and controlled by many uncertain factors, which is a very complicated problem. In this paper, the cloud model with obvious advantages in qualitative and quantitative transformation is introduced into the risk grade evaluation of foundation pit. The establishment of the model can not only realize the qualitative description of the risk class of foundation pit, but also can be converted into the corresponding quantitative value of each level (the digital characteristics of the cloud model). It makes up the defect that the previous classification methods cannot take the randomness and fuzziness of the index into account. In addition, the risk level model of foundation pit is based on probability theory, and the membership degree of the sample to the concept is automatically generated by the algorithm, avoiding the defect of the membership value determined by the subjective setting. The relation between randomness and fuzziness can be established. The application results show that the foundation pit construction risk classification model based on cloud model is more reliable than other analysis methods.

\section{Acknowledgments}

This study would not have been possible without financial supports the Ministry of Housing Urban-Rural Development under Grant NO. 2017-K4-032.

\section{References}

1. Huang H.W, Bian Y.H. (2005) Risk management in the construction of deep excavation engineering $[\mathrm{J}]$. Chinese Journal of Underground Space and Engineering, 1 (4): 611-614.

2. C hoi H.H, Cho H.N, Seo J.W. (2004) Risk assessment methodology for underground constriction projects[J]. Journal of Construction Engineering and Management, 130(2): 258-272.

3. He X.X, Zhou H.B, Y H. (2006) Construction risk identification and assessment of a deep foundation pit in Shanghai[J]. Chinese Journal of Geotechnical Engineering, 28 (Supp.): 1912-1915.

4. Todinov M.T. (2005) Reliability and risk models[M]. England: John Wiley \& Sons.

5. Guo Zhongwei. Risk analysis and decision[M]. Beijing: China Machine Press, 1987.

6. Qin B.J, Zhang S.K. (1998) Risk assessment of dynamic process[J]. Journal of Shanghai Jiaotong University, 32 (11): 17-20, 25.

7. Zhao H, Li Y.J, Song T. (1998) Study on engineering project risk management based on Bayesian network $[\mathrm{J}]$. Journal of Shenyang University of Technology (Social Sciences Edition), 1 (3): 239-244.
8. Yue X, Sun Z.L, Zhang Y.Q, et al. (2001) Data mining technology in web logs based on the cloud model[J]. Application Research of Computers, (11): 113-116.

9. Jiang R, Li D.Y, Chen H. (2000) Time series prediction with cloud models in DMKD $[\mathrm{J}]$. Journal of PLA University of Science and Technology (Natural Science), (5): 13 - 18 .

10. Xia Y.Y, Chen C.S, Chen J.P, et al. (2016) Dynamic Risk Assessment of Deep Foundation Pit Construction Based on Field Monitoring [J]. Chinese Journal of Underground Space and Engineering, 5(12): 1378-1384. 